neophytes in a very technical field, is not at all bad.

It was not the intent of the editors or authors to provide a handbook of procedure, statistical or otherwise; their job was rather to suggest ways of approaching research, possible refinements, relevant statistical procedures, all of which are carefully documented in extensive notes and footnote references to which the interested reader may go for further, more detailed information. To apply the cliche "mine of information" would be misleading; the volume is rather of the nature of a detailed report of the activities of an assay office. The suggestions of how and where to dig are there; the digging the student will have to do for himself.-LeRoy Charles Merritt, University of California.

\section{Flow of Scientific}

\section{Information}

The Flow of Information among Scientists: Problems, Opportunities, and Research Questions. Prepared by Columbia University, Bureau of Applied Social Research, May 1958. New York: The Bureau, 1958. 202p. (mimeographed).

This pilot study, prepared for the National Science Foundation, was undertaken to explore the possible contributions of research by interview methods to the problems of exchange of scientific information. Its purpose was to formulate questions and to identify heretofore undefined categories of phenomena. Special attention was, therefore, devoted to the more obscure of the services performed by the scientific communication system, and on the unplanned and apparently accidental mechanisms for performing them.

Seventy-seven scientists at one university were interviewed, including biochemists, chemists, and zoologists in substantially equal numbers. The interview outline was revised continuously during the study and its final version is included as an appendix. Average interview time was just under two hours. The sample was so limited as to make sophisticated statistical analysis ridiculous, so the analysis of the data in the report is essentially qualitative and discursive.

The scope set for the study was all the channels through which scientists exchange and gather information, and all functions which scientific communication facilities are called upon to perform.

Since so much emphasis has been placed upon means for finding answers to specific questions, special emphasis is laid, in this study, on instances in which scientists secured answers to specific questions in ways other than those designed for this purpose. Twenty-eight reports were obtained on information sought outside the "regular channels of search," primarily by asking other people. Of these about two-thirds dealt with details of procedure. A few involved performance of experiments or expert judgments but most of the remaining two-thirds were materials of the type that should normally appear in the literature and about half actually did involve asking someone else to provide the literature citations. The first chapter suggests as projects for further research: (1) to determine how adequately information from personal sources is available; (2) should more varieties of information be securable in print, or should informal channels be made more widely usable? (3) how can informal (i.e. personal) channels be made more widely usable? (4) should more be made available through print (a) by having more printed or (b) by making what is printed easier to find? (5) what makes published information hard to locate? (6) why is information of certain types seldom published?

Chapter II, dealing with the problem of keeping scientists abreast of current developments in their specialties, reports only reading and personal contacts, with reading of journals in the specialty as the primary tool of two-thirds of those reporting. The questions proposed for future research are: (1) Does any significant amount of current information fail to appear in the literature? (2) Why are published items missed? (3) In what fields are published items most likely to be missed? (4) What are the forms of personal communication that work? (5) How much access do scientists in varying positions have to personal communications? (6) What clues to pertinence of articles are lacking? 
(7) At what level of efficiency is scanning of journals done?, etc.

The other functions, covered in Chapter III, are review of the state of the art, establishing reliability of a source, redirecting attention to different approaches or aspects, eliciting feedback from other scientists, helping to assess the position of a topic within the current research market. The topics for research suggested in this chapter are: (1) What is incidence of communications serving the function? (2) How many of these involve forms of communication that are problematical? (3) How important to science were these experiences? (4) How did they come about? and (5) What are the corresponding experiences of those who lacked easy access to these sources?

Chapter IV, which provides supplementary comments on the main channels of communication, points out that the average number of journals read is thirteen, that biochemical and chemical literature is dispersed less than zoological literature. Similar miscellaneous notes are included on reviews, abstract journals, conferences, and personal contacts.

This study is interesting in that it represents an attempt by trained social scientists to develop a clearer statement of the nature of the problems of scientific communication and to isolate those that might profitably be studied. Unfortunately, despite the stress laid on isolating non-conventional forms of communication, there is little exposed here that is not common knowledge among the practitioners in the field of special library work or documentation, and the program of investigation might have profited from using the current management engineering technique of including in the survey team at least one person who is competent in the discipline being investigated. The fundamental problem in this type of approach to the problem of scientific communication is that it attempts to derive reliable data from the consensus of a group that does not include specialists in the field in which they are being queried. This, like asking visiting bankers what they think of the cooking on railway dining cars, may elicit consensus but may not necessarily point to valid action. This is best exemplified in the discussion of review journals (p. 140-145) in which of fifty-three men asked to list the distinguishing features of good and bad reviews, twenty-nine failed to give any and those that did give features for identifying bad reviews couched them in such general language as to be meaningless in operational terms.

Probably one of the most important features of this report is its recognition of the limitations of the method, or perhaps even the questions, in view of "the nature of specialization among the basic researchers. ..."-Ralph R. Shaw, Graduate School of Library Service, Rutgers University.

\section{Dorking Conference}

Proceedings of the International Study Conference on Classification for Information Retrieval. Held at Beatrice Webb House, Dorking, England, 13th-17th May, 1957. London: Aslib; New York: Pergamon Press, 1957. 147p.

The Proceedings of the International Study Conference on Classification for Information Retrieval, held at Beatrice Webb House, Dorking, England, May 13-17, 1957, makes widely available the principal addresses, discussions, conclusions, and recommendations of the Conference. The forty invited participants represented a broad national spectrum including France, Germany, India, Italy, the Netherlands, Unesco, the United Kingdom, and the United States. Invited representatives from the Soviet sphere did not attend.

It seems possible that the long-range significance of the Dorking Conference will not emanate so much from its own substantive achievements. The limitations of conferences of this kind in terms of valid research achievement are obvious. But as pragmatic devices to create a more conducive mental environment for cooperative research in needed areas, conferences of this kind find a level of reality and usefulness. In this sense, the addresses themselves at Dorking may be regarded as a kind of "busy" embroidery-work around this deeper, pragmatic function. They cover a wide range from pious generalities, to "chauvinism" concerning a particular system, to highly specialized 